\title{
The influence of mass customization and maker movement in the textile and apparel industry
}

\begin{abstract}
This mini review aimed at analyzing how mass customization and the Maker movement are modifying the production and consumption of textile and clothing goods. This paper focus on the consumer role in the production and consumption. Both mass customization and Maker movement propose a new role for the consumers, in which they actively participate in the construction, modification and manufacturing of different products supported by Information and Communication Technology (ICT) tools. In this sense, one sector that benefits most from this environment is the Textile and Apparel industry. It was noticed that Internet of Things, robotics, 3D printing, microprocessors and programming language learning are decisive elements in the diffusion of the Maker movement and mass customization within this industry. Consequently, the production systems and business models are becoming more intelligent and autonomous. One example of this model is the Smart Factory, a virtual integrative environment that allows the remote controlling and monitoring of all activities through virtual copies and the intensive use of ubiquitous technologies. The mini-factories, also considered a new production paradigm, are based on on-demand production. These consumers' movements and new paradigms will follow the rapid technological changings that will spread not only to production and industrial systems, but also to teaching and learning processes, social and cultural aspects.
\end{abstract}

Keywords: maker movement, mass customization, textile and apparel industry, information and communication technologies, prosumer
Volume 2 Issue 5 - 2017

\author{
Adriana Yumi Sato Duarte,' Regina Aparecida \\ Sanches, ${ }^{2}$ Franco Giuseppe Dedini ${ }^{3}$ \\ 'Faculty of Communication, Arts and Design, University of \\ Nossa Senhora do Patrocínio, Brazil \\ ${ }^{2} S$ chool of Arts, University of São Paulo, Brazil \\ ${ }^{3}$ Faculty of Mechanical Engineering, State University of \\ Campinas, Brazil
}

Correspondence: Adriana Yumi Sato Duarte, Faculty of Communication, Arts and Design, University of Nossa Senhora do Patrocínio, Praça Antônio Vieira Tavares, 73, Salto/São Paulo, ZIP Code 13320 219, Brazil, Tel 55 | |40288340,

Email adriana.duarte@ceunsp.edu.br

Received: June 28, 2017 | Published: August 17, 2017
Abbreviations: ICT, information and communication technologies; DIY, do-it-yourself; IoT, internet of things; QR Code, quick response code; RFID, radio frequency identification

\section{Introduction}

The adoption of Information and Communication Technologies (ICT) has changed the way designers develop new products and interact with consumers. ICT refers to the convergence between audiovisual systems, telephones and computer networks in a single set. Many technological advances have occurred in recent decades, such as the popularization of microcomputers, the development of the World Wide Web (WWW), the Internet as a user-friendly interface for browsing the WWW, social media, the storage of a large amount of data in cloud, Big Data and intelligent systems. ${ }^{1,2}$

The contemporary society organization challenges the traditional design model by proposing the need for decentralization and distribution around the world to be close to the local consumers. Thus, the product development must be a human-centered activity, in a dynamic co-construction to maximize the synergy among all stakeholders. $^{3}$

The technologies' democratization allowed the consumers to be elevated to an active role in the product development process. The Maker Movement permits users to express themselves by creating and constructing digital and tangible objects. ${ }^{4}$ The principle of the Maker Movement combines practical problem solving with the abstract concept of different disciplines. ${ }^{5}$

The Mass Customization is a management strategy that enables a company to provide a variety of combinations at a low cost and fast response capability. Mass customization can create value to products that makes the customer willing to pay more for custom products. ${ }^{6}$ The Mass Customization also requires the consumer involvement. In this perspective, customers engage in dialogue and interaction with suppliers throughout the design, production, delivery and consumption. ${ }^{7}$

The origin of the textile production is closely related to the origin of humanity. Clothing, as well as food and shelter, is considered a basic human need. In addition to this, it is a form of self-expression and sense of belonging that becomes even more important for individuals and social groups. ${ }^{8}$

The textile industry played and still plays an important role in the Industrial Revolution. The textile chain includes raw material, spinning, weaving/knitting, dyeing/printing, confectioning and selling. ${ }^{9}$

Based on this background, this mini review aims at analyzing how Mass Customization and Maker Movement-two emergent movements strongly related to a new production and consumption paradigm- are modifying the Textile and Apparel Industry. This paper focus on the consumer role in the product development, decision-making process and consumption.

The information and communication technology (ICT) in the textile and apparel industry: new production and consumption models

Described by ${ }^{10,11}$ as a networked society that takes advantage of globalization, telecommunication channels, culture of virtuality and disruptive models of time and space to stimulate individuals to 
perform multiple tasks. In this context, the consumer is becoming a "prosumer". The term "prosumer", created in the 1980s, combines the words "producer" and "consumer" to describe a consumer able to solve problems in a Do-It-Yourself (DIY) initiative. ${ }^{12}$ In the industrial production, the prosumers decide the product configuration or learn how to make their own product.

Custom orders can challenge companies with unpredictable peak demand, resulting in long waiting times, which in turn are a potential negative effect for consumers. On the other hand, these orders can help companies increase revenue and competitive advantage, improve cash flow, and reduce waste. Mass customization can also generate valuable data for product development, online marketing and campaigns. The shape of real-world objects can be analyzed through 3D scanners, which collect data to build digital models. These scanners facilitate the measurement of a human body for individualized products. In the future, 3D scanning and modeling can move directly into the home, giving consumers the ability to scan, build the 3D model and begin ordering custom clothing. Manufacturing, supply chain and logistics will benefit from the adoption of digital sensors and smart tags that will offer visibility, flexibility and control of product flows. This trend will be implemented by the Internet of Things (IoT), sensors, and intelligent analysis. ${ }^{13}$

Two Mass Customization production models will be widely used: the smart factory and the mini-factory. The smart factory integrates stakeholders in a virtual and collaborative environment, enables the remote control and monitoring through virtual copies of the physical environment and requires an intensive use of ubiquitous technologies in portable devices. Mini-factories are based on on-demand production. The production of yarns and fabrics, machinery and environmental conditions will be remote monitored using QR Code (Quick Response Code) and RFID (Radio Frequency IDentification) to access production data. The clothing confection stage can be reconfigured into a mini-factory, which encompasses the ordering, sampling, dyeing, cutting, sewing, finishing and packaging activities.

The Maker Movement is closely related to electronic textiles field. ${ }^{14}$ Electronic textiles are a contemporary craft that combines digital and material in an authentic and aesthetic way that connects computation-apparently abstract-and manual techniques-tangible and concrete. ${ }^{5,15}$

The teaching methods should also be adapted to meet these new trends. It will be necessary to introduce new methods of teaching, because the students will be active agents and will have control of their own learning ${ }^{4}$ State that Maker education presents more benefits and positive aspects than traditional teaching model, such as the collaborative environment and the exchange of information and experiences. Educators are introducing electronic textiles into the classroom to generate new, attractive, and more accessible contexts for electronics and computing. Report that the use of the Arduino Lily pad has successfully promoted the computer engineering. ${ }^{5}$

\section{Conclusion}

It is noticed that the consumer becomes a "prosumer", an active agent in the construction of values, in the process of product development and conscious consumption. The Maker Movement and mass customization are examples of this new role. Mass customization allows customers to individualize products. In the Textile and Apparel industry, customization will be possible by integrating technological tools such as 3D scanners so that clothes are produced exclusively for the client. In addition, the smart factory and the mini-factory will be the new factory configurations in the context of mass customization. The Maker movement is a way of creating and constructing digital and tangible objects. Electronic textiles are examples of the Maker Movement, in which the textile materiality and electronic capacity are combined into a single piece. Thus, the challenge of the different areas of knowledge linked to these new movements will be to accompany the repercussion of technological innovations in production, teaching methods, business models, consumer habits and social and cultural aspects in the coming years.

\section{Acknowledgements}

The authors thank CAPES for the financial support.

\section{Conflict of interest}

The authors declare that there is no conflict of interest.

\section{References}

1. Chan C, Holosko MJ. A review of information and communication technology enhanced social work interventions. Res on Soc Work Prac. 2016;26(1):88-100.

2. Luo Y, Bun J. How valuable is information and communication technology? A study of emerging economy enterprises. $J$ of World Bus. 2016;51(2):200-211.

3. Lu SCY, Elmaraghy W, Schuh G, et al. A Scientific Foundation of Collaborative Engineering. Annals of the CIRP. 2007;56(2):605-634.

4. Papavlasopoulou S, Giannakos MN, Jaccheri L. Empirical studies on the Maker Movement, a promising approach to learning: A literature review. Entertain Comp. 2017;18:57-78.

5. Kafai Y, Fields D, Searle K. Electronic textiles as disruptive designs: Supporting and challenging maker activities in schools. Harvard Ed Rev. 2014;84(4):532-556.

6. Shao X-F. Integrated product and channel decision in mass customization. IEEE Trans on Eng Manag. 2013;60(1):30-45.

7. Grimal L, Guerlain P. Mass customization in apparel industry-implication of consumer as co-creator. J of Econ \& Manag. 2014;15:105-121.

8. Ha-Brookshire J, Labat K. Envisioning textile and apparel research and education for the 21st century. International Textile and Apparel Association. USA; 2015. p. 38

9. Ülgen VS, Forslund H. Logistics performance management in textiles supply chains: best-practice and barriers. Int J of Produc and Perf Manag. 2015;64(1):52-75.

10. Bauman Z. Liquid modernity. 12th ed. John Wiley \& Sons; 2013. p. 240.

11. Castells M. The rise of the network society: The information age: Economy, society, and culture. 2nd ed. John Wiley \& Sons, USA; 2011. p. 656

12. Toffler A. The third wave. 2nd ed. New York: Bantam Books; 1981. p. 554.

13. Gandhi A, Magar C, Roberts R. How technology can drive the next wave of mass customization. Bus Tech Office. 2014. p. 1-8.

14. Posch I. E-textile tooling: new tools-new culture? J of Innov and Entrep. 2017;6(1):10.

15. Satomi M, Perner-Wilson H. Future Master craftsmanship: Where we want electronic textile crafts to go. ISEA, 2011. p. 14-21. 